bags and placed in iron trays, these trays being placed on racks in a closed room containing a charcoal burner. In this manner they are dried

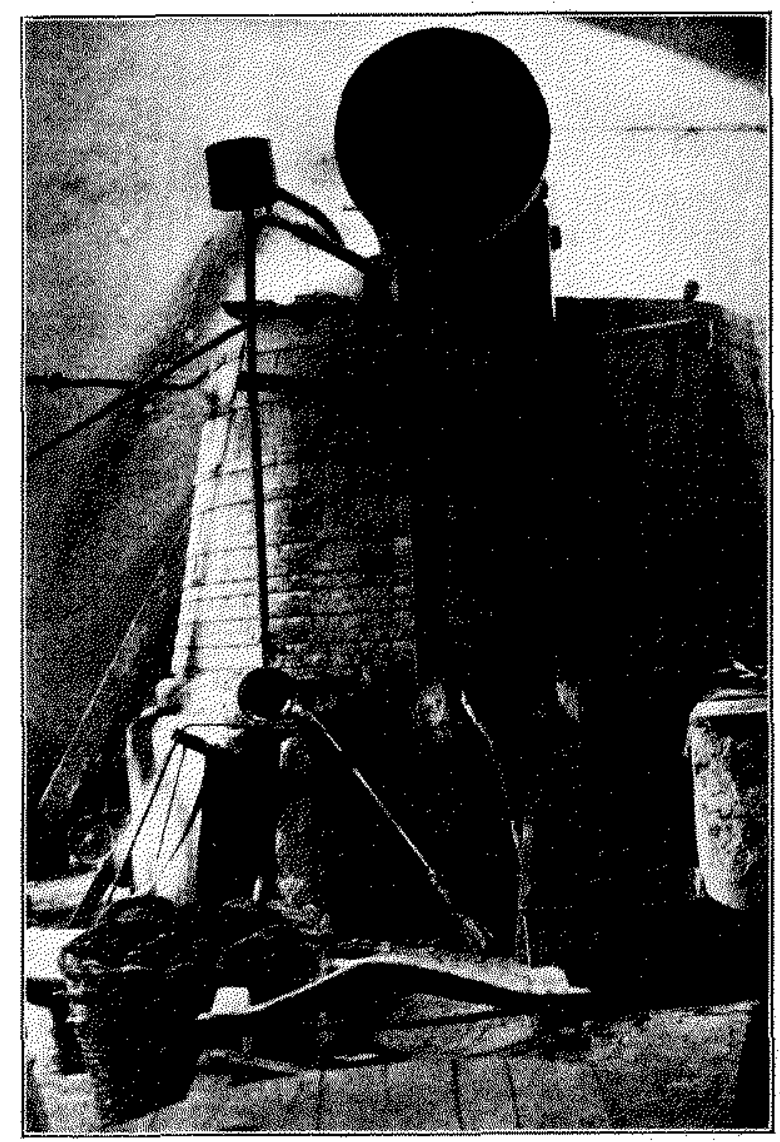

Fig. 11.-Vat used for precipitating citrate of lime.

down to a moisture content of a few per cent. The product is packed in hogsheads and shipped largely to the United States and England.

\section{TURPENTINE AND ITS ADULTERANTS,}

By Arthuk E. PaUL.

Received September 18, 1908.

In the turpentine forests of our southern states the custom is to cut a cup-shaped opening or "box" into the pine tree, about $\mathrm{xI}^{\prime \prime}$ across, 3 " wide, and $5 \frac{1}{2}$ " deep, having a triangular, or " $V$ ". shaped, upper surface. As this upper surfacecommonly called "rabbit's ear"- "bleeds," the juice, of about the consistency of glucose, runs into the "box" and is collected. At the end of a week the upper surface is cut afresh ("streak"), and such a new "streak" is cut every week for a season of nine to eleven months. The gum so ob- tained during the first year is called "virgin gum," and the opening made is called "virgin box."

The height of this opening is now some 18 " to $24^{\prime \prime}$. During the second year, the cutting of streaks is continued as before, but the opening is now called "yearling box," and the product "yellow dip." During the third year the opening is termed, in the east, "buck box," and in the west, "doe box." After the third year, the opening is called "pulling box," and the product is still "yellow dip." We have then: "yearling box yellow dip," "buck box yellow dip," "doe box yellow dip," "fourth year yellow dip," etc.

During all this time some of the gum hardens and adheres to the tree. This is scraped off, and is known as "scrape," or as "gum thus." When the "Herty" system is used, the gum, instead of running down into the "box," is-by means of two pieces of steel placed at an angle to each other and driven into the tree-made to run into a cup, hung just below the streak. In this system the product, from year to year, is practically "virgin gum."

All the products mentioned above: virgin gum, the various yellow dips, and gum thus, are called "crude turpentine" or "gum turpentine."

The scientist, however, designates these substances collectively as "turpentine." In fact, his definition of the word is: "the oleo-resinous exudate from certain species of "Pinus'."

By distillation, in the presence of water, this gum is separated into the non-volatile "rosin," and the volatile mixture of hydrocarbons, which is known scientifically as "oil of turpentine," and commercially as "spirits of turpentine," or more commonly, simply as "turpentine," and vulgarly as "turps," and sometimes, especially to distinguish it sharply from so-called wood turpentine, it is called "gim turpentine."

To recapitulate:

$$
\begin{aligned}
& \text { Scientifie term. Commetcial term. }
\end{aligned}
$$

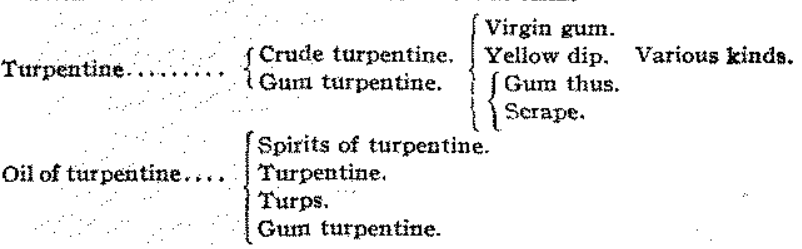

There is, then, some confusion in the use of the word turpentine, but scientific and commercial usage agree in applying the term only to the oleoresin referred to, or to the product derived therefrom. 
In this paper, the word will be used in its commercial sense, $i$. $e_{\text {. }}$, it will refer to the distillate from crude turpentine.

Turpentine is used in the manufacture of paints and varnishes. Its value, according to tradition, is due to its property of acting as a carrier of oxygen, thus aiding in the hardening of the oils and gums used. The correctness or fallacy of the theory has not yet been satisfactorily established.

Turpentine consists very largely of the hydrocarbon "pinene," and to a smaller extent, of "cymene." The former is readily polymerized by sulphuric acid, the latter not.

Specifications.-Because of the scarcity and comparatively high price of turpentine, and its liability to adulteration, the importance to the consumer, of assuring himself of the purity of the goods purchased, is apparent. Many large buyers, being aware of this fact, buy on specifications. These generally include a list of limits of physical constants, supposedly peculiar to turpentine. The specific gravity, flash point, behavior on distillation, polarization, color, residue on evaporation, and insolubility in sulphuric acid, are the most common limitations. The specifications also generally include a statement requiring the turpentine to be "pure."

Of these, all but the last-mentioned clause are superflious-the object of the specification not being to secure a certain quality of goods, but merely to exclude the possibility of sophistication, and are virtually methods for establishing purity. The "total solids" may be an exception, as they vary somewhat even in pure turpentine, and it may be well to specify limits, as they may be indicative of quality.

Wood Turpentines.-This designation is really a misnomer, since these products are not included in the definition given for turpentine. However, they are used in place of turpentine; according to most consumers, they answer the purpose equally well, and are of similar composition. Moreover, their use has become quite general, and they have been, and are, commonly designated as wood "turpentine."

Again, we must bear in mind that, because of the destruction of turpentine forests by methods of collection now in vogue, future dependence for turpentine supply will probably rest with wood turpentine.

Three markedly different varieties are at present manufactured:
"Stump" turpentine is made by destructively distilling stumps or other parts of dead resinous pine, or the so-called light wood. The products are wood alcohol, pyroligneous acid, tar, charcoal, and crude wood turpentine. This last, upon refining, yields a product which, but for its pungent, empyreumatic odor, is considered by users a very good substitute for turpentine. It contains considerable pinene, and notable quantities of cymene, more, indeed, than does "turpentine."

Steamed wood turpentine is made by distilling fat chips with stean and refining the distillate. The character of the product depends upon the kind of chips used, and more particularly upon the care exercised in its manufacture. Some specimens are in no way superior to the "stump" variety, while others are hardly distinguishable from true "gum" turpentine, the odor being very similar, in fact, more pleasant, and less pungent; and as to physical constants and chemical composition, they are practically identical therewith.

The third variety is interesting rather than coinmercially important, the output at the present time being insignificant. It may be called "Wood Pulp Turpentine," being a by-product in the manufacture of spruce or other wood pulp. That from spruce is composed almost entirely of cymene, which is an isomer of pinene. Its physical constants are similar to those of turpentine, but it is only very slightly affected by concentrated sulphuric acid. Its odor is strong and peculiar, but is really less pungent and less offensive than that of any of the other varieties, even the real "turpentine."

Since the only objection to wood turpentines, raised by practical users, is the odor, and as their price is but very little below that of turpentine, it follows that as a commercial adulterant they would have to be used in large quantities, so large as to be easily recognized by the odor. Notable quantities will be frequently indicated by the greater per cent. of total solids, the greater distillate from sulphuric acid in the method given below and the greater residue from direct steam distillation. Fractionation too will show a wider range of boiling points. Many specimens, especially of the "stump" kind, give distinct tests for rosin spirits.

Rosin Spirits.-This includes the lighter fractions obtained during the distillation of rosin, in the manufacture of rosin oil. It is commonly mentioned in treatises on paints and so forth, as one of the adulterants of turpentine. While it 
may be so employed, the writer has failed to find any evidence thereof, either analytically or commercially. For its detection the method of P. H. Conradson $^{1}$ is the most satisfactory, and nothing better can, at present, be suggested.

Petroleum Products.-Whatever may be the relative merits of the various kinds of turpentine, and whether the virtues ascribed to them are real or imaginary, the fact remains that they have certain distinct physical properties, and command certain market values, none of which are shared by any of the petroleum products. However, some of the latter have certain physical properties in common with turpentine, so that they are frequently employed by unscrupulous dealers for the purpose of adulteration. The number of turpentine substitutes now on the market, is legion. They consist almost invariably either of petroleum products pure and simple, or mixtures thereof with turpentine, wood turpentine, asphalt spirits, or similar products. Petroleum products are usually chosen, having a range of boiling points within that of turpentine.

Among the best known of these are:

"'Turpalin," price about 20 cents per gallon.

"Terrabentine," price about 20 cents per gallon.

"Sunoco Spirits," price about is cents per gallon.

"Chicago Turpentine," price about 30 cents per gallon.

"Norway Turpentine," price about 40 cents per gallon.

"Nuturps," price about 40 cents per gallon.

"“Turpteen Spirits," price about zo cents per gallon.

"Varnish Turpentine," price about 40 cents per gallon.

"Erco Spirits," price about I5 cents per gallon.

Whatever may be the relative desirability of turpentine as compared with petroleum products, the consumer should know which he is using. If he is satisfied with the properties of kerosene for his purpose, it will be econony for him to buy it as such, at the market value thereof. If he prefers to pay the extra price for turpentine, he is entitled to that article, and should, manifestly, assure himself that he is getting the pure substance, and is not paying turpentine prices for petroleum products.

As to the use of the term "turpentine," as in the case of the "Chicago Turpentine," or "Norway Turpentine," this is a misnomer, these products not being turpentine in any sense of the word.

1 J. Soc. Chem. Ind., 16, 519 (1897).

\section{METHODS OF DETERMINATION.}

Because of the comparatively low value of petroleum products as compared with pure turpentines, and because of their entire differences in chemical composition, as well as in physical properties, the determination of even trivial amounts of these substances is the principal problem in the examination of turpentines. The quantitative determination presents many difficulties, and chemists experience considerable trouble in deciding with certainty as to the presence or absence even of this form of adulteration.

As an example of hasty, incorrect, and almost amusing misinterpretation of analytical results, the following letter may be of interest. It came from a large user of turpentine in regard to a sample of wood turpentine, reported pure by us, and pronounced adulterated to the extent of 40 per cent. with petroleum oil, by their chemist:

"We wrote that we would report more fully to you on the sample of wood turpentine. Our chemist advises us as follows:

"Am sending you samples of the fractions separated in the distillation of the turpentine sample in question. Your attention is called to the low distillation points and gravities of Nos. I and 2 , and also their objectionable odor. These portions do not exist in good turpentine. Number 3 and number 4 are too low in gravity, due to the presence of lighter oils, boiling at the same point as the turpentine. Nos. 5, 6, and 7 should not comprise over 5 per cent. of the sample, whereas in this sample they make up 42 per cent. You will notice the heavy, greasy character of No. 7 . This certainly would not be a desirable turpentine sample." "

"In explanation of the above we would say that Nos. I and 2 distilled at below $300^{\circ}$ and comprised 7 per cent. of the sample. Nos. 3 and 4 distil at $302^{\circ}$ to $340^{\circ}$, and the gravity is 0.850 of the first and 0.852 of the second. Nos. 5, 6, and 7 have a gravity between 0.852 and 0.930 . No. 7 , which comprises 5 per cent. of the sample we sent him, is a dark red, vile-smelling liquor. ............"

The above statements are tabulated below for the sake of convenience:

Fraction. Nos. 1 and 2. No.3. No.4. Nos. 5 and 6. No. 7.

\begin{tabular}{|c|c|c|}
\hline $\begin{array}{l}\text { Per cent. .... } \quad 7 \\
\text { Remarks.... strong oder }\end{array}$ & & $\begin{array}{cc}37 & 5 \\
\text { dark; } & \text { vile odor } \\
\text { should not be over } 5 \%\end{array}$ \\
\hline 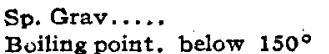 & $\begin{array}{l}0.850 \quad 0.852 \\
150^{\circ} \text { to } 170^{\circ}\end{array}$ & 0.852 to 0.930 \\
\hline
\end{tabular}
Boiling point. below $150^{\circ} \quad 150^{\circ}$ to $170^{\circ}$

A comparison of these results with those given 
in the table below will show that the chemist is making the erroneous assumption that the properties of turpentine and wood turpentine are identical, and these incorrect premises must necessarily lead to entirely incorrect conclusions.

The methods at present employed for detecting and determining petroleum products in turpentine are:

I. Fractionation with or without subsequent examination of the fractions by physical methods.

2. Polymerization with sulphuric acid and measurement of the residual oil.

3. Repeated polymerization with sulphuric acid and determination of the refractive index of residual oil.

4. Polymerization with nitric acid, and measurement of the residual oil.

Fractionation.-In carrying out this process the same details of procedure should always be employed, and the results compared with those on the same variety of turpentine of known purity. One variety of wood turpentine cannot be compared with another, nor either of them with pure gum turpentine.

F. W. Richardson and J. L. Bowen ${ }^{1}$ recommend fractionation and determination of the refractive indices of the fractions; but any method based on physical measurements cannot be relied on for quantitative work because of the different physical constants for different petroleum products. In the article referred to, the refractive index of turpentine is given as 1.470 to $I .473$, and of petroleum products as I.4I to I.46, which brings the minimum for the former, and the maximum for the latter entirely too close together.

A series of distillations of known mixtures, the boiling points of like fractions being noted, together with their readings in the butyro-refractometer, gave the following:

\begin{tabular}{|c|c|c|}
\hline & $\begin{array}{r}\text { Wo } \\
\text { pul } \\
\text { B.P. }\end{array}$ & $\begin{array}{l}\text { ood } \\
\text { dp. } \\
-\mathrm{Rf}\end{array}$ \\
\hline Start...... & 170 & 085 \\
\hline $10 \mathrm{cc} . . . .$. & 171 & 85 \\
\hline $20 \mathrm{cc} . \ldots \ldots$ & 171 & 85 \\
\hline 30 cc...... & 171 & 86 \\
\hline $40 \mathrm{cc} . . . .$. & 171 & 87 \\
\hline 50 c....... & 171 & 187 \\
\hline $60 \mathrm{cc} . . . \ldots$ & 172 & 287 \\
\hline $70 \mathrm{ce} \ldots \ldots$ & 172 & 288 \\
\hline $80 \mathrm{cc} . \ldots$. & 173 & 388 \\
\hline $90 \mathrm{cc} \ldots \ldots \ldots$ & 175 & 590 \\
\hline Residue... . & - & -99 \\
\hline Sp. gr..... . & & 625 \\
\hline Refract.... & 95 & 5 \\
\hline Solids..... & 0 & 0.6 \\
\hline
\end{tabular}

\begin{tabular}{cc}
$\begin{array}{c}\text { Steam } \\
\text { wood. }\end{array}$ & $\begin{array}{c}\text { Stump } \\
\text { wood. }\end{array}$ \\
B.P.-Rf. & B.P.-Rf. \\
15056 & 12460 \\
15657 & 15068 \\
15757 & 15770 \\
15757 & 16170 \\
15757 & 16370 \\
15757 & 16870 \\
15857 & 17170 \\
16057 & 17471 \\
16259 & 17773 \\
16760 & 18379 \\
\hline 80 & -99 \\
.8660. & .8670 \\
58 & 77 \\
1.2 & 3.5
\end{tabular}

It is interesting to note that in the case of "kerosene adulterant," which is a petroleum product, chosen commercially for the purpose of adulterating turpentine, and of "elaine oil," a high-grade conmercial kerosene, an addition of 5 per cent. cannot be recognized sharply. "Erco spirits," which is a lighter fraction, is easily detected qualitatively by this method. "Hexane," a very light petroleum ether, is not used for adulteration, but an addition of 5 per cent. can be readily recognized as above.

Altogether this method is not satisfactory. The products most frequently used may escape even qualitative detection, and the lighter products could be nuch more easily, and just as surely, found by a mere flash point determination.

Polymerization with Sulphuric Acid.-The method of shaking a measured quantity of the sample with concentrated sulphuric acid, and reading the residual oil after a given length of time, is used very largely by paint chemists. The method is dangerous, on account of possible explosions, the results at best very little better than a guess, especially if the adulterant is present in small quantities only.

The modification devised by McCandless ${ }^{2}$ is quite ingenious, and fairly satisfactory in many cases. He treats a Ioo cc. sample gradually with 50 cc. of concentrated sulphuric acid, shaking and cooling; repeats the process until a butyrorefractometer reading of 22 or less is reached, and then measures the surviving oil.

The method has, however, several drawbacks: the operation must be carried on repeatedly; the loss is considerable. Again, a petroleum fraction might be used having a refractometer reading greater than 22 and cause confusion, or escape detection, and a fraction heavy enough not to be carried over by steam, certainly would not be found.

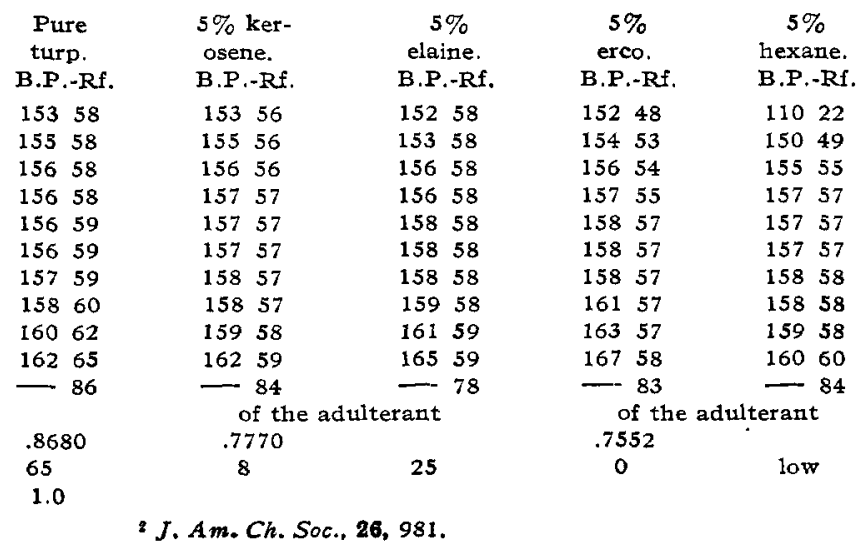


Polymerization with Fuming Nitric Acid.-The method of Burton ${ }^{1}$ cannot be recommended, being very dangerous, exceedingly trying and timeconsuming and, at best, not at all accurate. His details, when tried experimentally, will be found to be quite impracticable for a laboratory method.

The modification, or rather the combination, of old methods, employed by the writer with entire success, is comparatively easy, is safe and rapid, includes all the possible fractions of petroleum products, and gives almost quantitative results, except in the case of very light naphtha, which, to the writer's knowledge, is never employed for purposes of adulteration. Even in this case as much as 50 per cent. of the amount present is readily separated, and as little as I per cent. of added ordinary mineral product may be determined with certainty.

The appended table shows laboratory results, obtained on various known substances and mixtures:

\begin{tabular}{|c|c|c|c|c|c|c|c|c|}
\hline & $\begin{array}{l}\text { Wood } \\
\text { pulp. }\end{array}$ & p & $\begin{array}{l}\text { Pure } \\
\text { turper- } \\
\text { tine. }\end{array}$ & $\begin{array}{l}1 \% \\
\text { kero- } \\
\text { sene. }\end{array}$ & $\begin{array}{c}5 \% \\
\text { kero- } \\
\text { sene. } 1\end{array}$ & $\begin{array}{l}5 \% \\
\text { hexan }\end{array}$ & $\begin{array}{l}5 \% \\
\text { elaine }\end{array}$ & $\begin{array}{l}5 \% \\
\text { leavy } \\
\text { min- } \\
\text { eral } \\
\text { oil. }\end{array}$ \\
\hline $\begin{array}{l}\text { Steam distil.... } \\
\text { Refractometer. }\end{array}$ & . trace & $\begin{array}{r}4.5 \\
\text { high }\end{array}$ & $\begin{array}{l}0.3 \\
\text { high }\end{array}$ & $\begin{array}{r}1.0 \\
\text { high }\end{array}$ & $\begin{array}{r}1.0 \\
\text { high }\end{array}$ & $\begin{array}{r}1.0 \\
\text { high }\end{array}$ & $\begin{array}{l}4.5 \\
78\end{array}$ & $80^{9.0}$ \\
\hline${ }_{2} \mathrm{SO}_{4}$ distil.... & 70 & 17 & 8.0 & 10.0 & 14.0 & 12.0 & 10.0 & 7 \\
\hline Refractometer. & . 100 & 90 & 77 & 60 & 48 & 63 & 50 & 90 \\
\hline $\begin{array}{l}\text { HNO, treatm't. } \\
\text { Refractometer. }\end{array}$ & & none & 3.5 & $\begin{array}{l}1.5 \\
9\end{array}$ & $\begin{array}{l}4.5 \\
0.0\end{array}$ & $\begin{array}{l}3.0 \\
\text { low }\end{array}$ & $\begin{array}{l}5.0 \\
18\end{array}$ & 5. \\
\hline efractometer & 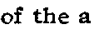 & 11tere & ent & 8 & 8 & low & 25 & 60 \\
\hline
\end{tabular}

The method in detail is as follows: Ioo cc. sample, in a suitable flask (500 cc. Jena Kjeldahl answers nicely), is distilled in a current of live steam. The residue and distillate are transferred to separatory funnels and the water tapped off. The distillate is returned to the flask, treated with $500 \mathrm{cc}$. of concentrated sulphuric acid very gradually, shaken, and carefully cooled (McCandless's method). $25 \mathrm{cc}$. water are added and the mixture distilled with steam, to a total of roo cc. With pure turpentines the amount of oil is uniformly $8 \mathrm{cc}$, an excess indicating adulteration. This oil is added to the residue from the first direct steam distillation.

A volume of fuming nitric acid, equal to three times that of the combined residues, is placed in a separatory funnel and thoroughly cooled in ice water. The combined oils are now added, drop by drop, shaking carefully and keeping cold. After all the oil has been added, allow to rest a few moments and draw off the acid layer. Wash

$1 A m . C h . J ., 12,102$. the remaining oil once with fuming nitric acid, twice with ordinary strong nitric acid, and finally several times with water. Measure the volume.

The refractometer readings may advantageously be made on the various products obtained, but are by no means essential.

With pure turpentine a residuum of about 0.5 per cent. will be obtained, and allowance for this must always be made.

In the case of wood turpentine no such residuum is obtained, or at most, a mere trace, and no correction is necessary.

In the above series of experiments, then, the results, after making the correction, are:

\begin{tabular}{|c|c|c|}
\hline & $\begin{array}{l}\text { Added, } \\
\text { per cent. }\end{array}$ & $\begin{array}{l}\text { Found, } \\
\text { per cent. }\end{array}$ \\
\hline Kerosene adulterant... & 1.0 & 1.0 \\
\hline adulterant. & 5.0 & 4.0 \\
\hline Elaine oil............ & 5.0 & 4.5 \\
\hline Mineral oil, heavy............ & 5.0 & 4.5 \\
\hline Hexane $\ldots \ldots \ldots \ldots \ldots \ldots \ldots \ldots$ & 5.0 & 2.5 \\
\hline
\end{tabular}

showing that with such petroleum products as are commercially enployed, the method yields almost quantitative results, irrespective of the physical constants thereof, or of the turpentine employed. As little as one per cent. is found without any trouble. With exceedingly light products which are not used, however-the results would be low.

IABORATORY OB

MARINER AND HOSKINS, Chicago.

\section{THE DETERMINATION OF TOTAL, FIXED AND VOLATILE ACIDS IN WINES.}

BY Julius HoRtvet.

Received September 21, 1908.

Considered from the standpoint not only of the food chemist but of the industrial chemist as well, determinations of total, fixed and volatile acids in wines are among the most important that are required in a complete course of analysis. These determinations are necessary not only for the judging of wines in accordance with legal standards of purity, but they also afford at times a very crucial insight into conditions relating to soundness or quality. At an earlier date than the latter part of the last century these considerations were not so much emphasized, doubtless because they were but little understood.

The first methods of analysis were of such a character as one might expect in the beginnings of our knowledge of fermented liquors as a class. The first known method of determining volatile acids 